\title{
Mechanistic and Cost-Effectiveness Analysis of Cement Treated Bases in Flexible Pavement
}

\author{
Mena I. Souliman ${ }^{1}$, Nitish R. Bastola ${ }^{1}$, Waleed A. Zeiada ${ }^{2}$ \\ ${ }^{1}$ The University of Texas at Tyler \\ 3900 University Boulevard, Tyler, TX 75701 RBS 1008, USA \\ msouliman@uttyler.edu; nbastola@patriots.uttyler.edu \\ ${ }^{2}$ University of Sharjah \\ Sharjah, P.O. Box: 27272, UAE \\ wzeiada@sharjah.ac.ae
}

\begin{abstract}
Pavement performance is a key parameter that governs the serviceability of road networks. This performance is heavily influenced by the pavement construction materials such as asphalt binder and aggregates. The use of proper aggregates results in enhanced structural stability and greater long-term performance of pavements. However, due to the rapid construction of roads around the world, aggregates used in the base layer are often treated with various stabilizing agents such as cement. In this study, various observations are made based on the use of cement as stabilizing agent and traffic speeds over the pavement. Various mechanistic analyses are performed using the 3-D Move Analysis software and the comparative studies are presented in between the treated and untreated bases and their effect on fatigue performance. The analysis showed that the use of cement as a stabilizing agent increased the pavement performance up to $96 \%$ for fatigue cracking compared to untreated base layers. The cost-effectiveness analysis also showed that the use of stabilizing agent would reduce the long-term cost of pavement as compared to untreated bases.
\end{abstract}

Keywords: Pavements, Base Layer, Aggregates, Stabilizing Agents, Cement, Fatigue Cracking, Mechanistic Analysis, Costeffectiveness.

\section{Introduction}

Hot mixed asphalt (HMA) pavement consists typically of 3-layers: HMA surface layer, base layer, and subgrade. The base layer, composed of aggregates, is an important layer in terms of structural performance. The load transferred from the surface of the pavement ultimately goes to the base, therefore, there is a need for the base layer to be stiff enough to withstand the variable traffic loads and various climatic conditions [1]. Various methods are being utilized for enhancing the strength of the base layer against traffic loading and climate conditions. The multiple layers in the pavement structure are required to withstand the traffic loads and various distresses generated. The base layer must be strong and have rigidity to not allow distortion, lateral flow, nor consolidation. The base course layer is designed to have adequate thickness to reduce traffic damage over time [2]. Additionally, the base layer can be made either bounded or unbounded. A bounded layer refers to a base layer where some sort of stabilizing agent or treatments agent is utilized to make the layer more robust and stable. In contrast to bound layer, an unbound layer does not utilize any kind of external agent, but rather the strength of the base layer solely depends on the strength of the aggregates. Various kinds of stabilizing agents are utilized in bounded bases, such as lime, cement, and asphalt. The use of these additives is very beneficial in the construction of HMA pavement as they reduce distresses in the pavement structure. Pavement performances are also affected by environmental conditions, therefore, a proper study regarding the utilization of these kinds of stabilizers must be made through various mechanistic and costeffectiveness analyses. The study presented in this paper compares various aspects of utilizing cement treated bases and untreated bases.

\section{Literature Review}

Stabilization is the process of adding a cementing agent to the soil or crushed rock to produce materials that have greater strength than the original unstabilized ones [3,4]. There are two types of base layers generally used in the construction of flexible asphalt pavements, which includes unbound aggregate bases that consists of untreated granular materials, and bound aggregate bases that consist of granular material bounded physically or chemically by a stabilizing agent (e.g. cement, asphalt 
emulsion or foamed asphalt $[3,5,6]$. The use of a stabilized base results in an increased performance of base layer with a greater stability and proper aggregate interlock.

Granular base layers have low elastic modulus values, which require both asphalt and base layers with higher flexible pavement thickness in order to avoid premature failure due to rutting or fatigue cracking. The construction cost of asphalt layer is higher than the construction cost of other pavement layers [7]. Using treated base layers with higher elastic moduli reduces the thickness of the pavement layers, decreases construction costs, and conserves natural resources. Various researchers have used various stabilizing agents in HMA pavement, however; the basic purpose of using the stabilizing agent remains the same.

Wang investigated the performance of flexible pavements with stabilized bases. The performance of experimental pavement was observed at the Pennsylvania Transportation Research Facility. Crushed stone, aggregate bituminous concrete, aggregate cement, and aggregate lime- pozzolana were used as base course for the pavement with the loading conditions of 2.4 million 18-kip equivalent axle load. The data were analyzed with respect to the pavement serviceability index and distress conditions of roughness, rutting, and cracking. Various models were developed and evaluated which illustrated an increased pavement performance using stabilizing agents [8].

Similarly, Faysal et al. mixed RAP with different Portland cement content in order to meet the resilient modulus requirements of $1947 \mathrm{kPa}(300 \mathrm{psi})$ to be used in pavement construction project $[9,10]$. The test results showed that $4 \%$ cement content will meet the minimum strength requirement. In a similar study, but using fly ash for stabilization of the RAP, Saride et al. found that $80 \%$ RAP replacing virgin aggregates can be stabilized with $40 \%$ fly ash to meet both the resilient modulus and unconfined strength requirements of base material for low volume roads [11].

In addition to the structural benefits of the treated base layers of pavement, various economic savings are obtained. Francois et al. conducted a study on five field sections located on Route 165 in Rhode Island (RI) which were evaluated as part of a controlled study conducted by RI Department of Transportation (RIDOT) to evaluate long-term field performance using stabilized base. It was found that it is cost-effective to use bases stabilized with Portland cement, geogrids, asphalt emulsions, or $\mathrm{CaCl} 2$, over non-stabilized RAP base since the life cycle cost of the untreated RAP base section appeared to be the lowest of all the pavement sections analyzed in the study in terms of predicted performance [5]. Cement treated base layer was compared with untreated virgin aggregate layer Bodhgire et al. They found that the estimated cost for flexible pavement designed with cement treated base layer is $52 \%$ lower than that designed using granular aggregates base layer [7].

Koroma studied the life cycle cost analysis of pavement sections containing treated open-graded bases and compared them to traditional dense-graded untreated bases using predicted performance of the MEPDG [12]. Treated open-graded bases were found to have higher life cycle cost. He concluded that pavement sections with treated layer will have to go an extra 30 years without maintenance in order to have identical life cycle costs as those with untreated dense-grade bases.

The various studies presented above showed that the addition of additive or using base treatments resulted in a great impact on the pavement structural capacity and its life. These studies have clearly provided analysis related to the strength, but the long-term impact on the cost and benefit are rarely described. This paper quantifies the recurring cost using mechanistic-empirical analysis based on bottom-up fatigue cracking.

\section{Study Objective}

Base treatments are one of the most important construction practices to increase the overall pavement performance in addition to their potential long-term cost-effectiveness benefits. Various stabilizing materials are utilized for base treatments. This study focuses on the use of cement as stabilizing agent. Cement treated base was considered in determining the improved pavement performance using mechanistic analysis, which then was utilized to investigate the cost-effectiveness of such treatments using two different binder grades at four different traffic speeds. 


\section{3-D Move Mechanistic Analysis}

One of the most powerful software packages in the design of flexible pavements is referred to as the 3-D Move Analysis. Analysis. It was developed at the University of Nevada, Reno under the cooperative agreement with Federal Highway Administrative Agency. Complex surface loading, such as multiple loads and non-uniform tire pavement contact stress, are are handled by the program with the continuum finite layer approach [13]. Advanced applications of the software include estimation of damage under-off-road farm vehicles and estimation of pavement performance at the intersection. Some of the of the salient features of the 3-D Move Analysis software are adjustable loading configuration and tire, modelling of 3-D surface stresses, and analyzing non-generic tire and axle configuration. This study utilized the 3-D Move Analysis software to the utmost level to find the performance of the flexible pavement base when it accounts for the bottom-up fatigue cracking for two different grade of binder and three different temperatures with two different base sections of untreated and cement treated.

This research used the HMA properties determined in the National Cooperative Highway Research Program (NCHRP) 9-44 A (14). The test results used in this study are the results presented in the project report NCHRP Report 762. The values required in the 3-D Move Analysis, such as dynamic modulus |E*|, phase angle $(\varnothing)$, and fatigue regression coefficient are derived from the same research project. The research effort of the NCHRP 9-44 A included the characterization of different PG asphalt binders. This study considered two PG asphalt binders which are PG 64-22 and PG 76-16.

Table 1 shows the dynamic modulus values and phase angle of the PG 64-22 at different temperatures and frequencies. The corresponding regression coefficient k1, k2 and $\mathrm{k} 3$ of the generalized fatigue model of PG 64-22 are 0.000558, 3.876197 and 0.875271 , respectively [14].

Table 1: Dynamic Modulus (E*) and Phase Angle values for PG 64-22 Binder [14].

\begin{tabular}{|c|c|c|c|c|c|c|}
\hline \multirow[b]{3}{*}{$\begin{array}{c}\text { Temp } \\
\text { (C) }\end{array}$} & \multicolumn{6}{|c|}{ Dynamic Modulus (kPa) } \\
\hline & \multicolumn{6}{|c|}{ Frequency $(\mathrm{Hz})$} \\
\hline & 0.1 & 0.5 & 1 & 5 & 10 & 25 \\
\hline-10 & $17,243,787$ & $19,512,162$ & $20,311,954$ & $21,980,485$ & $22,945,751$ & $24,228,176$ \\
\hline 5 & $10,328,346$ & $13,058,670$ & $14,175,620$ & $17,092,103$ & $18,436,580$ & $20,112,006$ \\
\hline 22 & $2,654,481$ & $3,867,959$ & $4,481,592$ & $6,219,071$ & $7,011,968$ & $8,108,234$ \\
\hline 38 & 675,686 & $1,020,424$ & $1,241,056$ & $2,006,374$ & $2,482,113$ & $3,419,799$ \\
\hline \multirow[t]{2}{*}{55} & 193,053 & 310,264 & 386,106 & 648,107 & 779,108 & $1,041,108$ \\
\hline & \multicolumn{6}{|c|}{ Phase Angle $(\varnothing)$ (degree) } \\
\hline-10 & 9 & 8 & 8 & 8 & 8 & 6 \\
\hline 5 & 19 & 16 & 15 & 14 & 14 & 11 \\
\hline 22 & 34 & 30 & 27 & 22 & 20 & 17 \\
\hline 38 & 24 & 25 & 27 & 28 & 28 & 30 \\
\hline 55 & 13 & 15 & 18 & 22 & 25 & 28 \\
\hline
\end{tabular}

Similarly, for PG 76-16 asphalt binder, the fatigue regression coefficients k1, k2 and k3 are 0.000558, 3.876197 and 0.875271 , respectively [14]. Table 2 shows the dynamic modulus and phase angles values of the PG 76-16 asphalt binder. 
Table 2: Dynamic Modulus (E*) and Phase Angle values for PG 76-16 Binder [14].

\begin{tabular}{|c|c|c|c|c|c|c|}
\hline \multirow{3}{*}{$\begin{array}{c}\text { Temp } \\
\text { (C) }\end{array}$} & \multicolumn{6}{|c|}{ Dynamic Modulus $(\mathrm{kPa})$} \\
\hline & \multicolumn{6}{|c|}{ Frequency $(\mathrm{Hz})$} \\
\hline & 0.1 & 0.5 & 1 & 5 & 10 & 25 \\
\hline-10 & $20,429,165$ & $22,945,751$ & $24,014,439$ & $26,889,552$ & $27,772,081$ & $29,488,876$ \\
\hline 5 & $12,445,036$ & $14,734,096$ & $15,878,625$ & $18,684,791$ & $19,608,689$ & $21,146,220$ \\
\hline 22 & $5,419,279$ & $7,604,917$ & $8,611,551$ & $11,693,508$ & $13,134,512$ & $14,030,830$ \\
\hline 38 & $1,247,951$ & $1,778,847$ & $2,102,901$ & $3,468,063$ & $4,136,854$ & $5,357,226$ \\
\hline \multirow[t]{2}{*}{55} & 330,948 & 558,475 & 689,476 & $1,110,056$ & $1,344,478$ & $1,771,953$ \\
\hline & \multicolumn{6}{|c|}{ Phase Angle $(\varnothing)$ (degree) } \\
\hline-10 & 7.1 & 9.7 & 10.8 & 11.6 & 11.8 & 12.8 \\
\hline 5 & 9.5 & 12.9 & 14.4 & 15 & 16 & 16.3 \\
\hline 22 & 14.5 & 17.7 & 20.3 & 24.7 & 26.2 & 29.9 \\
\hline 38 & 28.2 & 31.3 & 31.4 & 34.7 & 34.5 & 34 \\
\hline 55 & 31.2 & 27.2 & 26.7 & 22.4 & 20.1 & 19.9 \\
\hline
\end{tabular}

\section{Mechanistic Analysis of Bottom-Up Fatigue Cracking}

Among the various types of the distress conditions in flexible pavements, bottom-up fatigue cracking is one of the major forms of distress. Bottom-up fatigue cracking is a series of interconnected cracks developed in the surface of the HMA surface or base under repeated traffic loading. Crack initiates at the bottom of the asphalt layer and propagates towards the surface of the pavement. The mechanistic performance of base layer under various treatments, such as cement is expected to perform better. Figure 1 shows the bottom-up fatigue cracking performance of two different types of mixtures, one with binder grade PG 64-22 and the other one with PG 76-16 under three different speeds of 40, 72, and 104 kilometer per hour.

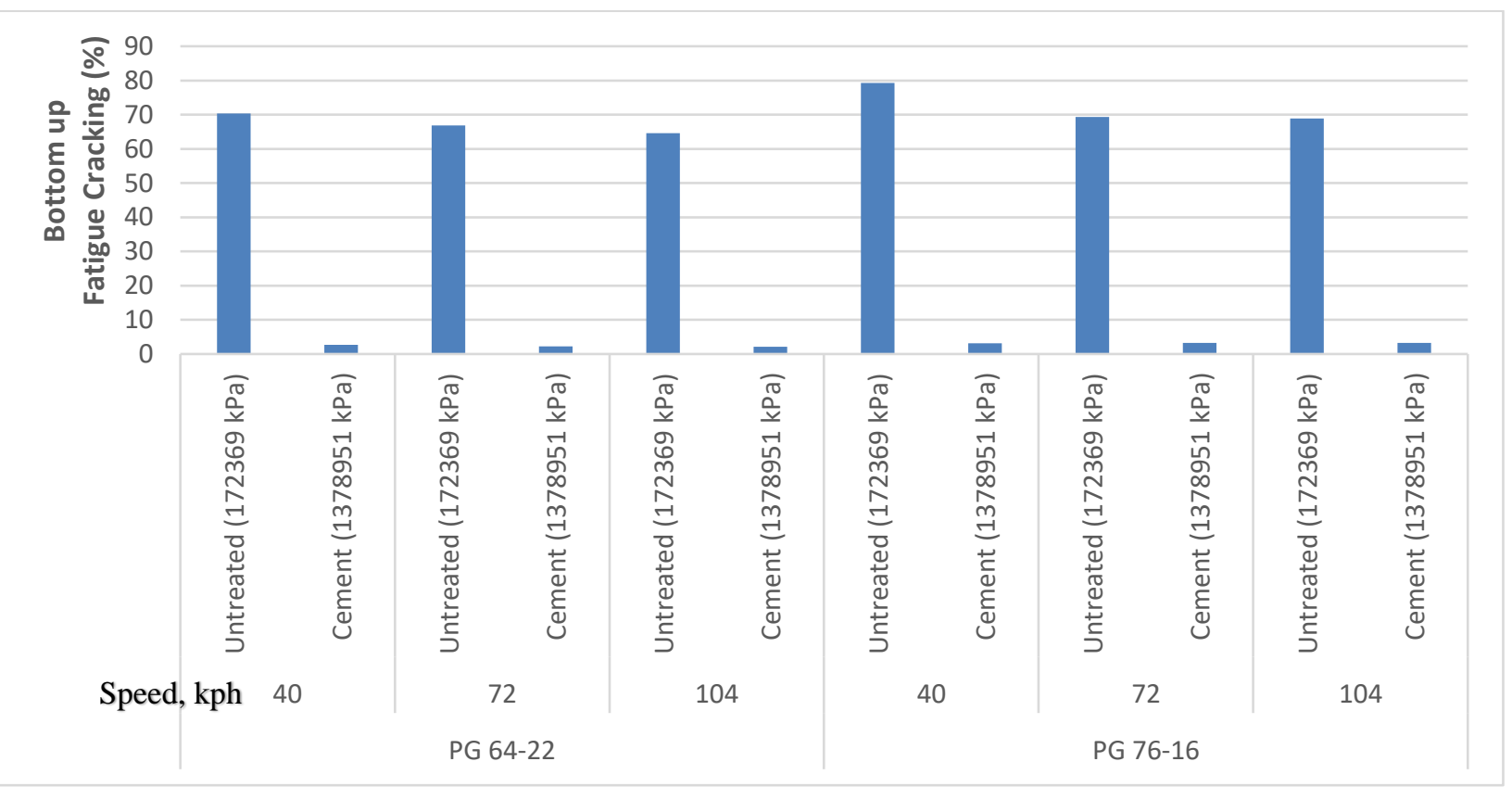

Fig. 1: Bottom-up fatigue performance of pavement with various base treatments. 
It can be observed from Figure 1 that all treated base layers had superior fatigue cracking resistance as compared to untreated sections. Cement treatment had the low predicted fatigue cracking. It can also be noticed that pavement structures structures with stiffer asphalt binder grade (PG 76-16) are more susceptible to fatigue cracking than softer asphalt binder grade (PG 64-22). The fatigue cracking of both PG 64-22 and PG 76-16 asphalt binders decreases as the traffic speed increases due to the viscoelastic nature of asphalt pavements where pavement structures act as a strong material under high high loading frequency (high traffic speed) whereas it acts as a weak material under low loading frequency (low traffic speed). $\quad$ In order to mathematically quantify the performance of base treatments with regard to their improved fatigue cracking resistance, a Fatigue Cracking Reduction Percentage (FCRP) was calculated as follows:

$$
\text { FCRP }=\frac{\text { Fatigue cracking for untreated base section }- \text { fatigue cracking of treated base section }}{\text { Fatigue cracking for untreated base section }} * 100 \%
$$

Table 3 shows the calculated FCRP for all structures illustrated in Figure 2. All presented cement treated bases at different traffic speeds and binder grades had an average FCRP of 96\%. This indicates that cement base treatment has better performance than the untreated bases.

Table 3: Bottom-Up Fatigue Cracking Performance of various base treatments.

\begin{tabular}{|c|c|c|c|c|}
\hline $\begin{array}{l}\text { Binder } \\
\text { Grade }\end{array}$ & $\begin{array}{l}\text { Speed } \\
\text { Limit } \\
(\mathrm{kph})\end{array}$ & Base treatment & $\begin{array}{c}\text { Bottom Up } \\
\text { Fatigue Cracking } \\
(\%)\end{array}$ & $\begin{array}{c}\text { Fatigue Cracking } \\
\text { Reduction } \\
\text { Percentage } \\
\text { (FCRP) }\end{array}$ \\
\hline \multirow{6}{*}{ PG 64-22 } & \multirow{2}{*}{40} & Untreated $(172369 \mathrm{kPa})$ & 70.38 & N/A \\
\hline & & Cement $(1378951 \mathrm{kPa})$ & 2.65 & 96.2 \\
\hline & \multirow{2}{*}{72} & Untreated $(172369 \mathrm{kPa})$ & 66.82 & N/A \\
\hline & & Cement $(1378951 \mathrm{kPa})$ & 2.19 & 96.7 \\
\hline & \multirow{2}{*}{104} & Untreated $(172369 \mathrm{kPa})$ & 64.56 & N/A \\
\hline & & Cement $(1378951 \mathrm{kPa})$ & 2.17 & 96.6 \\
\hline \multirow{6}{*}{ PG 76-16 } & \multirow{2}{*}{40} & Untreated $(172369 \mathrm{kPa})$ & 79.27 & N/A \\
\hline & & Cement $(1378951 \mathrm{kPa})$ & 3.19 & 96 \\
\hline & \multirow{2}{*}{72} & Untreated $(172369 \mathrm{kPa})$ & 69.37 & N/A \\
\hline & & Cement $(1378951 \mathrm{kPa})$ & 3.25 & 95.3 \\
\hline & \multirow{2}{*}{104} & Untreated $(172369 \mathrm{kPa})$ & 68.88 & N/A \\
\hline & & Cement $(1378951 \mathrm{kPa})$ & 3.21 & 95.3 \\
\hline
\end{tabular}

*N/A relates to original untreated base layer

\section{Cost-Effectiveness Analysis of Base Treatments}

Cost-effectiveness analysis plays an important role to determine the performance versus the cost of using different base treatment applications. In this study, cost-effectiveness analysis was conducted for cement treated bases in terms of its improved fatigue resistance as compared to untreated bases. The following is the mathematical representation of the estimated cost-effectiveness of base treatments in terms of bottom-up fatigue cracking:

$$
\text { Cost - effectiveness of base treatments in terms of fatigue }
$$

$$
=\frac{\text { Undamaged Area of Pavement due to Bottom }- \text { up fatigue cracking }}{\text { cost per mile of the pavement }}
$$


Upon determining the cost-effectiveness of each base treatment, cost-effectiveness ratio can also be determined as follows:

$$
\text { Cost }- \text { Effectiveness Ratio }=\frac{\text { Treated Cost Effectiveness }}{\text { Unteated Cost Effectiveness }}
$$

In order to calculate the cost-effectiveness illustrated above, the following two subheadings (6.1 and 6.2) illustrate the required calculations of both remaining undamaged pavement and the cost per mile of pavement.

\section{1. Remaining Undamaged Pavement Condition}

By the end of the design life of 20 years, the remaining undamaged surface area of pavement due to bottom-up fatigue cracking can be estimated as the total surface area illustrated in Figure $2(1.600 \mathrm{~m} * 3.66 \mathrm{~m})$ minus the predicted bottom-up fatigue cracking as shown in Table 3.

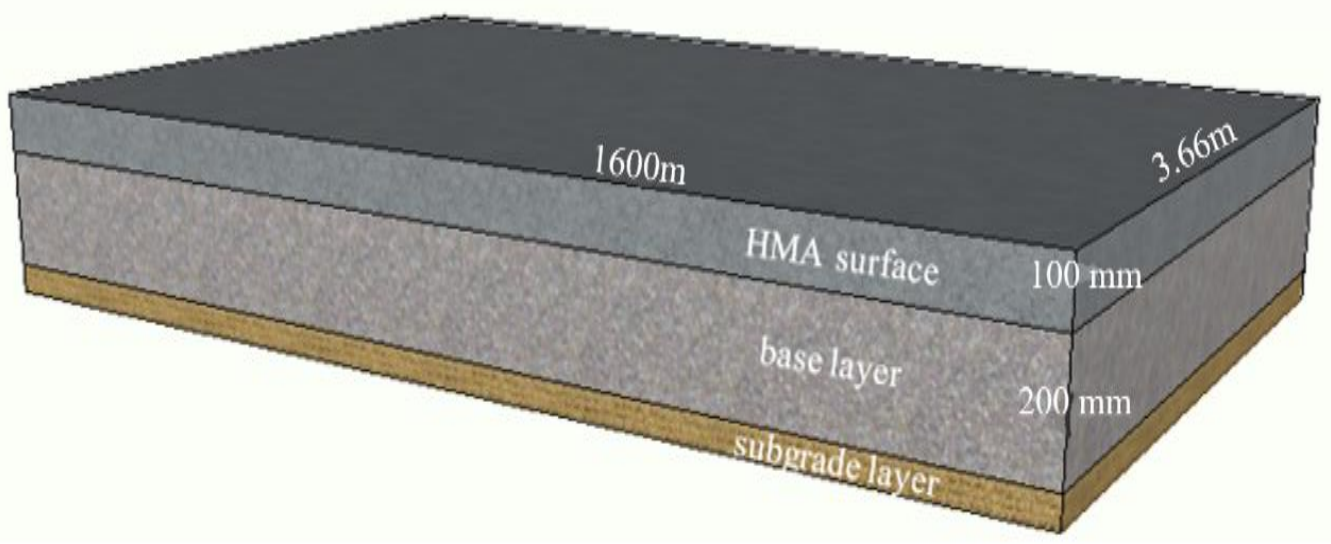

Fig. 2: Pavement structure considered in the study (Dimensions).

\section{2. Cost Per Mile of Pavement}

In order to estimate the cost of each base treatment and compare it to the untreated base, the cost of one ton of each of the base treated layer was calculated given the fact the unit price for aggregates, cement are $\$ 22, \$ 153.69$ per ton, respectively [15]. In this analysis, all treatments were added to the base aggregates at a rate of $2 \%$ by weight of the aggregates. This leads to the cost of base layer calculated as the following (assuming that the cost of plant and equipment are same for all types of bases).

- 1 Ton of Untreated Base Layer: \$22/ton

- 1 Ton of Cement Treated Base: $2 \%$ of $\$ 153.69 /$ ton $+98 \%$ of $\$ 22 /$ ton $=\$ 24.64 /$ ton

For 8 inches of base layer thickness as shown in Figure 4, the required quantity is calculated as width $(3.66 \mathrm{~m}) \times$ length $(1600 \mathrm{~m}) \times$ thickness $(0.2 \mathrm{~m}) \times$ density $(2472.42 \mathrm{~kg} / \mathrm{m} 3)=2895.7$ tons.

Therefore, the cost required for paving with the given base and treatments can be calculated as:

- Cost to pave $1.6 \mathrm{~km}$ of untreated base case $=\$ 63,705$

- $\quad$ Cost to pave $1.6 \mathrm{~km}$ of cement treated base case $=\$ 71,349$ 


\section{3. Cost- Effectiveness of Various Base Treatments in Terms of Bottom-Up Fatigue Cracking}

Based on the calculated remaining undamaged area of pavement due to bottom-up fatigue cracking and the cost per one mile of each base-treatment, cost-effectiveness for cement treated bases in terms of bottom-up fatigue cracking were calculated based on equation 2. Overall results are shown in Table 4.

Table 4: Cost- Effectiveness of Various Base Treatments for Bottom-Up Fatigue Cracking.

\begin{tabular}{|c|c|c|c|c|c|c|}
\hline $\begin{array}{l}\text { Binder } \\
\text { Grade }\end{array}$ & $\begin{array}{l}\text { Speed } \\
\text { Limit } \\
(\mathrm{kph})\end{array}$ & Base Treatment & $\begin{array}{c}\text { Remaini } \\
\text { ng } \\
\text { undamag } \\
\text { ed } \\
\text { surface } \\
\text { area }\left(\mathrm{m}^{2}\right)\end{array}$ & $\begin{array}{l}\text { Cost to } \\
\text { pave } \\
1.6 \mathrm{Km} \\
(\$)\end{array}$ & $\begin{array}{c}\text { Cost- } \\
\text { Effectiveness } \\
\text { (using } \\
\text { equation 2) }\end{array}$ & $\begin{array}{c}\text { Cost- } \\
\text { Effectiveness } \\
\text { Ratio (using } \\
\text { equation 3) }\end{array}$ \\
\hline \multirow{6}{*}{ PG 64-22 } & \multirow{2}{*}{40} & Untreated $(172369 \mathrm{kPa})$ & 1743.53 & 63705 & 0.03 & N/A \\
\hline & & Cement $(1378951 \mathrm{kPa})$ & 5730.35 & 71349 & 0.08 & 2.93 \\
\hline & \multirow{2}{*}{72} & Untreated $(172369 \mathrm{kPa})$ & 1953.09 & 63705 & 0.03 & N/A \\
\hline & & Cement $(1378951 \mathrm{kPa})$ & 5757.42 & 71349 & 0.08 & 2.63 \\
\hline & \multirow{2}{*}{104} & Untreated $(172369 \mathrm{kPa})$ & 2086.12 & 63705 & 0.03 & N/A \\
\hline & & Cement $(1378951 \mathrm{kPa})$ & 5758.6 & 71349 & 0.08 & 2.46 \\
\hline \multirow{6}{*}{ PG 76-16 } & \multirow{2}{*}{40} & Untreated $(172369 \mathrm{kPa})$ & 1220.24 & 63705 & 0.02 & N/A \\
\hline & & Cement $(1378951 \mathrm{kPa})$ & 5698.56 & 71349 & 0.08 & 4.17 \\
\hline & \multirow{2}{*}{72} & Untreated $(172369 \mathrm{kPa})$ & 1802.98 & 63705 & 0.03 & N/A \\
\hline & & Cement $(1378951 \mathrm{kPa})$ & 5695.03 & 71349 & 0.08 & 2.82 \\
\hline & \multirow{2}{*}{104} & Untreated $(172369 \mathrm{kPa})$ & 1831.83 & 63705 & 0.03 & N/A \\
\hline & & Cement $(1378951 \mathrm{kPa})$ & 5697.38 & 71349 & 0.08 & 2.78 \\
\hline \multicolumn{6}{|c|}{ Overall Cost-Effectiveness Ratio of Cement Treated Base } & 2.96 \\
\hline
\end{tabular}

$* \mathrm{~N} / \mathrm{A}$ relates to original untreated base layer

The cost-effectiveness analysis of the base treatment in terms of bottom-up fatigue cracking shows that the use of base treatments is more economical compared to untreated bases. It can be noticed that the use of cement treatment has the best cost-effectiveness in comparison to untreated bases at different traffic speeds using both asphalt binder grades. The costeffectiveness ratio of all base treatments is found to be higher using stiffer asphalt binder and for higher traffic speed cases (Table 4).

\section{Conclusions and Recommendations}

The purpose of this study was to conduct a mechanistic comparative analysis between treated and untreated bases in order to evaluate bottom-up fatigue cracking resistance. The base treatment considered in this study was cement treatment. In addition, cost-effective analysis was performed to investigate if such treatment was worthwhile considering their cost versus their improved field performance. Based on both mechanistic and cost-effectiveness analyses, the following conclusions are drawn:

- In terms of bottom-up fatigue cracking performance, all treated base layers had superior fatigue cracking resistance as compared to untreated sections. Cement treatment had the highest average FCRP of $96 \%$. 
- It can also be concluded that pavement structures with stiffer asphalt binder grade (PG 76-16) were more susceptible to fatigue cracking than softer asphalt binder grade (PG 64-22).

- Fatigue cracking decreased as the traffic speed increased due to the viscoelastic nature of asphalt pavements, where pavement structures act as strong material under high frequency loading (high traffic speed) but it acts as a weak material under low frequency loading (low traffic speed).

- Cost-effectiveness analysis showed that the use of cement treated base resulted in the highest cost effectiveness considering bottom-up fatigue cracking. The overall cost-effectiveness ratio of cement was 2.96 times the untreated base for the bottom-up fatigue cracking.

Therefore, it can be concluded that the use of base treatments could potentially contribute to an overall improved fatigue cracking resistant pavement structures. In addition, such treatments present improved cost-efficiency in base construction practices. Furthermore, this research reports the preliminary mechanistic and cost-effectiveness analysis of various base treatments based on the Texas Department of Transportation (TXDOT) practices, hence, further study based on other countries practices along with other form of distresses such as rutting and reflective cracking can lead to a geographically diverse verification of the above mentioned analysis.

\section{References}

[1] A. A. Francois, "Evaluating the impact of different types of stabilized bases on the overall performance of Flexible Pavements." Rowan University, 2016.

[2] D. N Little, T. Scullion, P. B. V. S. Kota, and J. Bhuiyan, "Identification of the Structural Benefits of Base and Subgrade Stabilization.” No. FHWA/TX-94/1287-2. 1995.

[3] S. Jaritngam, O. Somchainuek, and P. T. Neerananon, "Feasibility of laterite-cement mixture as pavement base coarse aggregate," Iranian Journal of Science Technology. Transactions of Civil Engineering, vol. 38 (C1+), pp. 275, 2014.

[4] Z. Wu, X. Chen, and X. Yang, "Finite element simulation of structural performance on flexible pavements with stabilized base/treated subbase materials under accelerated loading," 2011.

[5] Francois, Andraé, Ayman Ali, and Yusuf Mehta, "Evaluating the impact of different types of stabilised bases on the overall performance of flexible pavements," International Journal of Pavement Engineering, vol. 20, pp. 938-946, 2018.

[6] M. Faysal, M. S. Hossain, S.B. Salah, S. Bhattacharjee, B. Thian and, M.S. Khan, "Characterization of the GeoEnvironmental Properties of Untreated or Cement Treated Recycled Base Materials in Pavement Base Layer Applications," Geotechnical Frontiers 2017, pp. 415-423, 2017.

[7] R. Bodhgire, A. Shinde, and V. Kakade, "Cost Comparison of Flexible Pavement Designed with Cement Treated Base and Granular Base," 2019.

[8] M. C. Wang, "Performance Analysis for Flexible Pavement with Stabilized Base," Transportation Research Board. vol. 888. pp. 70-76.

[9] M. Faysal, M. Mahedi, A. Aramoon and, B.Thian. "Determination of the structural coefficient of different combinations of cement-treated/untreated recycled base materials," Geotechnical and Structural Engineering Congress, 2016.

[10] American Association of State and Highway Transportation Officials, AASHTO 307-99, Determining the Resilient Modulus of Soils and Aggregate Materials, 2017.

[11] S. Saride, D. Avirveni, S.C.P. Javvadi, A. Puppala, and L.R. Hoyos. "Evaluation of fly ash treated reclaimed asphalt pavement for base/subbase applications", vol. 45, pp.401-411, 2015.

[12] A. A. Koroma, "Evaluation of the performance and cost-effectiveness of pavement sections containing open-graded base courses," 2011.

[13] R.V. Siddharthan, J. Yao, and P. E. Sebaaly, "Pavement Strain from Moving Dynamic 3-D Load Distribution." Journal of Transportation Eng., ASCE, vol. 124, pp.557-566, 1998. 
[14] M. Witczak, M. Mamlouk, M. Souliman and W. Zeiada, "NCHRP REPORT 762: Laboratory Validation of an Endurance Limit of Asphalt Pavement," Transportation Research Board, Washington D.C, 2013.

[15] Texas Department of Transportation, (12 June 2019) Average Low Bid Unit Prices, [Online]. Available: https://www.txdot.gov/business/letting-bids/average-low-bid-unit-prices.html. 